\title{
Stabilization of Metal Nanoparticle Catalysts via Encapsulation in Mesoporous Zeolites
} by Steam-Assisted Recrystallization

Rasmussen, Kristoffer Hauberg; Goodarzi, Farnoosh; Christensen, David Benjamin; Mielby, Jerrik Jørgen; Kegnæs, Søren

\section{Published in:}

ACS Applied Nano Materials

Link to article, DOI:

10.1021/acsanm.9b02205

Publication date:

2019

Document Version

Peer reviewed version

Link back to DTU Orbit

Citation (APA):

Rasmussen, K. H., Goodarzi, F., Christensen, D. B., Mielby, J. J., \& Kegnæs, S. (2019). Stabilization of Metal Nanoparticle Catalysts via Encapsulation in Mesoporous Zeolites by Steam-Assisted Recrystallization. ACS Applied Nano Materials , 2(12), 8083-8091. https://doi.org/10.1021/acsanm.9b02205

\section{General rights}

Copyright and moral rights for the publications made accessible in the public portal are retained by the authors and/or other copyright owners and it is a condition of accessing publications that users recognise and abide by the legal requirements associated with these rights.

- Users may download and print one copy of any publication from the public portal for the purpose of private study or research.

- You may not further distribute the material or use it for any profit-making activity or commercial gain

- You may freely distribute the URL identifying the publication in the public portal 


\section{Article}

Subscriber access provided by DTU Library

\section{Stabilization of Metal Nanoparticle Catalysts via Encapsulation in Mesoporous Zeolites by Steam-Assisted Recrystallization}

Kristoffer H. Rasmussen, farnoosh goodarzi, David B. Christensen, Jerrik Mielby, and Søren Kegnæs

ACS Appl. Nano Mater., Just Accepted Manuscript • DOI: 10.1021/acsanm.9b02205 • Publication Date (Web): 02 Dec 2019

Downloaded from pubs.acs.org on December 3, 2019

\section{Just Accepted}

"Just Accepted" manuscripts have been peer-reviewed and accepted for publication. They are posted online prior to technical editing, formatting for publication and author proofing. The American Chemical Society provides "Just Accepted" as a service to the research community to expedite the dissemination of scientific material as soon as possible after acceptance. "Just Accepted" manuscripts appear in full in PDF format accompanied by an HTML abstract. "Just Accepted" manuscripts have been fully peer reviewed, but should not be considered the official version of record. They are citable by the Digital Object Identifier (DOI®). "Just Accepted" is an optional service offered to authors. Therefore, the "Just Accepted" Web site may not include all articles that will be published in the journal. After a manuscript is technically edited and formatted, it will be removed from the "Just Accepted" Web site and published as an ASAP article. Note that technical editing may introduce minor changes to the manuscript text and/or graphics which could affect content, and all legal disclaimers and ethical guidelines that apply to the journal pertain. ACS cannot be held responsible for errors or consequences arising from the use of information contained in these "Just Accepted" manuscripts. 


\title{
Stabilization of Metal Nanoparticle Catalysts via
}

\section{Encapsulation in Mesoporous Zeolites by Steam-}

\section{Assisted Recrystallization}

\author{
Kristoffer H. Rasmussen, Farnoosh Goodarzi, David B. Christensen, Jerrik Mielby* and Søren \\ Kegnces*
}

Technical University of Denmark, Kemitorvet bygning 207, 2800 Kgs. Lyngby, Denmark

Keywords: encapsulated nanoparticles, mesoporous zeolites, methanation, hydrogenation, steamassisted recrystallization.

\begin{abstract}
Zeolite encapsulated metal nanoparticle catalysts hold great promise for several green and sustainable processes, ranging from environmental remediation to renewable energy and biomass conversion. In particular, the microporous zeolite framework keeps the nanoparticles in a firm grip that can control selectivity and prevent sintering at high temperatures. While progress in the synthesis of mesoporous zeolites continues, the encapsulation of metal nanoparticles remains a challenge that often requires complex procedures and expensive additives. Here, we report a general method to encapsulate both base and noble metal nanoparticles inside the internal voids of a compartmentalized mesoporous zeolite prepared by carbon templating and steam-assisted


recrystallization. This results in a remarkable shell-like morphology that facilitates the formation of small metal nanoparticles upon simple impregnation and reduction. When the materials are applied in catalysis, we for instance demonstrate that zeolite encapsulated Ni nanoparticles are highly active, selective and stable catalysts for $\mathrm{CO}_{2}$ methanation (49\% conversion with 93\% selectivity at $450^{\circ} \mathrm{C}$ ). A reaction where catalysts often suffer from sintering due to the high reaction temperatures. While the introduction of $\mathrm{Ni}$ nanoparticles prior to the steam-assisted recrystallization results in the formation of inactive nickel phyllosilicates, noble metals such as Pt do not suffer from this limitation. Therefore, we also demonstrate the synthesis of an active catalyst prepared by the formation of Pt nanoparticles prior to the shell synthesis. We tested the zeolite encapsulated Pt nanoparticles for hydrogenation of linear and cyclic alkenes with increased chain length. The catalysts are active for hydrogenation of oct-1-ene (66\% conversion) and cyclooctene (79\% conversion) but inactive for the large cyclododecane ( $<1 \%$ conversion), which show that this type of catalyst is highly selective in size selective catalysis. All catalysts are characterized by XRD, TEM, XPS and $\mathrm{N}_{2}$ physisorption.

\section{Introduction}

Zeolites have many remarkable properties and find extensive use in heterogeneous catalysis. ${ }^{1,2}$ They are well-known for their Lewis and Brønsted acidity ${ }^{3,4}$ as well as their ability to encapsulate cations, complexes and metals in their crystalline microporous framework ${ }^{5-7}$. In the particular case of metal nanoparticles, there may be several reasons to encapsulate them inside zeolites. For instance, the zeolite framework may control the nanoparticle size, which results in a high metal dispersion. The zeolite framework may also protect the nanoparticles against sintering caused by particle migration and coalescence $\mathrm{e}^{8-10}$ or impose a strict size and shape selectivity by excluding 
molecules (reactants, intermediates or products) that are too large to diffuse in and out of the zeolite. ${ }^{5,11-14}$ Furthermore, zeolite encapsulated metal nanoparticles may benefit from the unique metal-support interface that is in close proximity to the active sites of the zeolite framework. ${ }^{15}$

Although many of the properties of zeolites relates to their microporous framework, the micropores may also cause limitations when it comes to large or bulky substrates. If the substrates and products are about the same size as the micropores, they will constantly be in contact with the pore wall, which will slow down the diffusion. For this reason, the rate of diffusion within a zeolite can be orders of magnitude lower than both molecular and Knudsen diffusion. ${ }^{16}$ It is important to underline that the problem of diffusion is the same whether the reaction occurs on an acidic or metal active site inside the zeolite catalyst.

In general, there are two approaches to overcome diffusion limitations. The first approach is to increase the effective diffusivity by increasing the pore size of the zeolite. Over the last 20 years, much effort has therefore been devoted to the synthesis of large- and extra-large pore zeolites. ${ }^{17}$ The second approach is to decrease the mean diffusion path length, either by decreasing the size of the zeolite crystals ${ }^{18}$ or by introducing an additional system of mesopores. ${ }^{19-22}$ The method to synthesize mesoporous zeolites typically includes dealumination, ${ }^{23,24}$ desilication $^{21,25-27}$ or templating using either hard ${ }^{28-32}$ or soft templates. ${ }^{33-36}$

Despite great technological, environmental and economic interest, general methods for the encapsulation of metal nanoparticles in zeolites are still not well established. In general, the poor diffusion of solvated metal precursors in small- and medium-pore zeolites (8- and 10-membered rings, respectively) preclude post-synthetic encapsulation by simple methods such as impregnation and ion exchange, ${ }^{5,37}$ whereas the incorporation of metal nanoparticles during crystallization often rely on expensive additives or complicated reaction procedures. ${ }^{10,38-40}$ 
Encapsulation of metal nanoparticles in situ in microporous zeolites have been accopmplished by several research groups which provide the size selectivity from the zeolite network ${ }^{37-40}$. The encapsulation of metal nanoparticle in mesoporous zeolite catalysts is an area of much ongoing research. ${ }^{13,41-45}$ For instance, Laprune et al. ${ }^{42}$ recently encapsulated nickel phyllosilicates in multi-hollow silicalite-1 crystals. The encapsulated nickel phyllosilicates were then reduced to Ni nanoparticles and tested for methane steam reforming at $700{ }^{\circ} \mathrm{C}$. Although the encapsulated Ni nanoparticles showed a high stability against sintering, the researchers also concluded that the catalytic activity of the encapsulated Ni nanoparticles suffered from poisoning by amorphous silica species remaining from the synthesis. Additionally, Li et al. ${ }^{46}$ developed a way to encapsulated Pt in a macroporous nanoreactor with a microporous yolk-shell by first impregnating a conventional silicalite-1 zeolite which then could undergo recrystallization to provide the encapsulated Pt in the macroporous interior of the zeolite providing sinter-stable nanoparticles. Generally, supporting metals in open mesopores enhance diffusion of molecules compared to conventional zeolites, however, it results in a lower size/shape selectivity for the reaction when compared to microporous zeolites ${ }^{47}$. Due to the size of the channels, introduction of the solvated metal precursors in mesopores by simple impregnation is easier compared to medium and small pore zeolites. Gu et al. ${ }^{48}$ exploited the mesopores in a ZSM-5 zeolite to encapsulate Pt nanoparticles and then convert it into a microporous zeolite to provide size selective catalysis.

In our work, we present a general method to encapsulate metal nanoparticles inside a highly mesoporous zeolite interior with a microporous zeolite shell providing both size selectivity and sinter-stable metal particles. The mesoporous zeolite was prepared by carbon templating, which 
allowed for easy impregnation with metal precursors. Formation of a microporous shell with preservation of the highly mesoporous interior was accomplished by steam-assisted recrystallization resulting in the remarkable compartmentalized zeolite. The synthesis allowed for supporting metal nanoparticles in a highly mesoporous interior while still benefitting from the micropores in the shell.Compared to conventional zeolite synthesis, steam-assisted crystallization also provides an attractive method to increase the yield, produce less waste and avoid phase separation. ${ }^{49-51}$ We demonstrate the successful encapsulation of both base and noble nanoparticles (Ni and Pt, respectively) and show the effect of supporting the metal both before and after the steam-assisted recrystallization. We tested the Ni containing zeolites in $\mathrm{CO}_{2}$ methanation, which is a promising power-to-gas technology, but suffers from sintering of metal particles at the high operating temperatures ${ }^{15}$. Here, we showed that encapsulation in the zeolite with the shell result in the most active with sinter-stable Ni particles.

The shell encapsulated Pt nanoparticles were tested for the size-selective hydrogenation of linear and cyclic alkenes and showed that the catalyst is highly selective in size selective catalysis. Figure 1 shows a schematic outline of the method. 


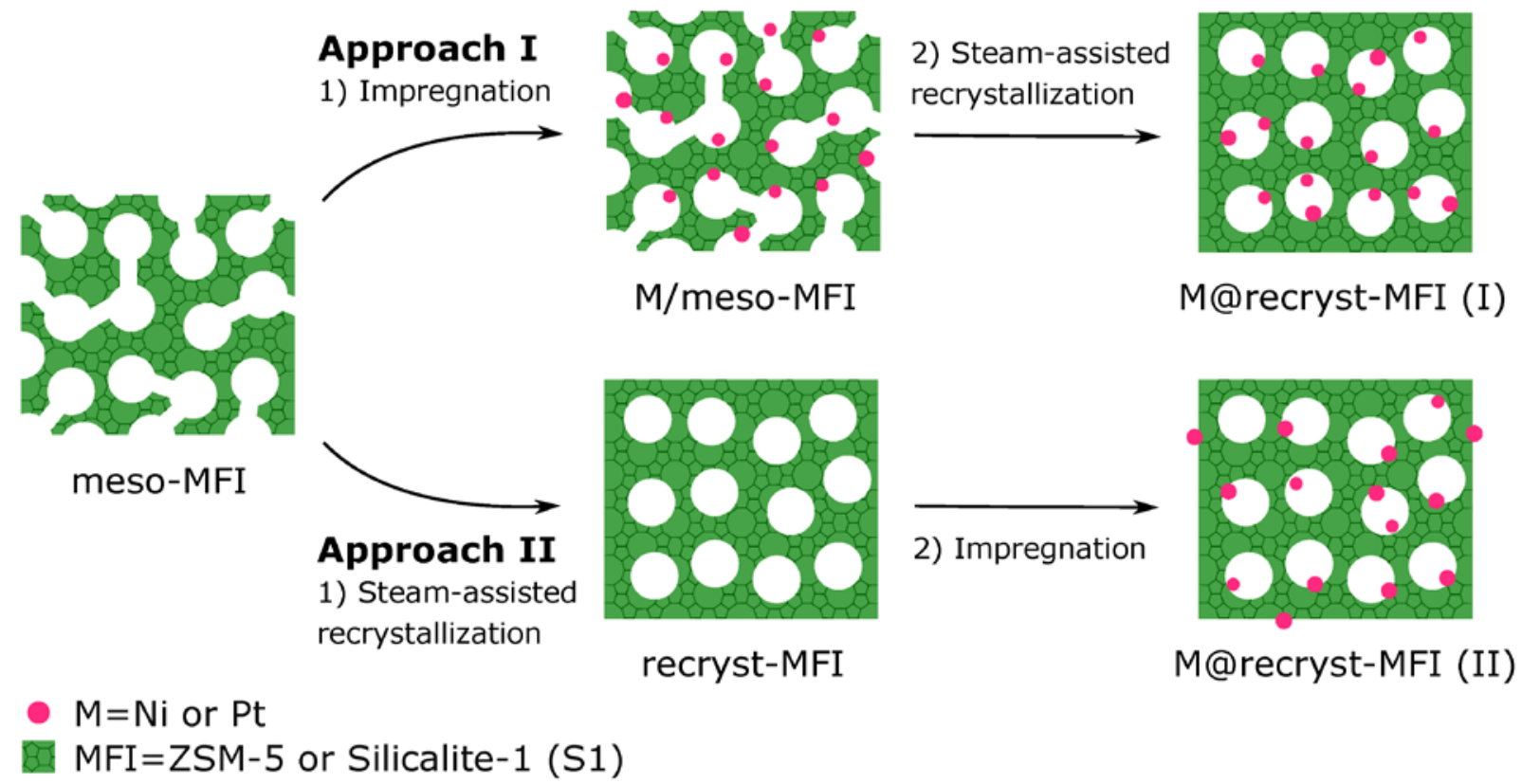

Figure 1. Schematic outline of a general method to encapsulate metal nanoparticles in zeolites.

\section{Experimental section}

Synthesis of mesoporous ZSM-5 and silicalite-1 (S-1): Following the procedure by Jacobsen et $a l,{ }^{29}$ a pre-dried carbon template (Carbon Black Pearls, BP2000, 2 g) was impregnated with an aqueous solution of tetrapropylammonium hydroxide (TPAOH, $1 \mathrm{M}, 7.2 \mathrm{ml}$ ) in a Teflon beaker. For ZSM-5, $\mathrm{NaAlO}_{2}(0.016 \mathrm{~g})$ was dissolved in the TPAOH solution prior to impregnation. The impregnated carbon template was left to dry at room temperature overnight. The template was then impregnated with TEOS $(4.4 \mathrm{~mL})$ and left to dry at room temperature overnight once more. The beaker with the carbon-silica composite materials was then placed inside a Teflon lined stainless steel autoclave filled with $15 \mathrm{ml}$ distilled water for the steam-assisted synthesis. The autoclave was heated to $180{ }^{\circ} \mathrm{C}$ and kept for $72 \mathrm{~h}$. After cooling to room temperature, the solid material was collected by filtration and washed with water until neutral $\mathrm{pH}$. The samples were dried at $80{ }^{\circ} \mathrm{C}$ 
for $12 \mathrm{~h}$ and finally calcined at $550{ }^{\circ} \mathrm{C}$ for $20 \mathrm{~h}$ to obtain a fine white solid product (meso-S1 or meso-ZSM-5).

Steam-assisted recrystallization (synthesis of recryst-ZSM-5 and recryst-S1): meso-ZSM-5 or meso-S1 (0.5 g) was ground in a mortar, impregnated with varying amounts of TPAOH and dried at room temperature overnight. The dry zeolites were then impregnated with varying amount of TEOS and dried at room temperature overnight once more. The exact amounts and ratio of zeolite to TPAOH and TEOS are listed in Table 1. The dried zeolites were then placed in a Teflon beaker inside a Teflon lined stainless steel autoclave containing $15 \mathrm{ml}$ of water for the steamassisted recrystallization. The autoclave was heated at $180{ }^{\circ} \mathrm{C}$ for $72 \mathrm{~h}$. The product was collected by filtration, washed with water until neutral $\mathrm{pH}$, dried at $80{ }^{\circ} \mathrm{C}$ for $12 \mathrm{~h}$ and finally calcined at $550{ }^{\circ} \mathrm{C}$ for $20 \mathrm{~h}$ to obtain a fine white product.

Encapsulation of metals (approach I): As-synthesized meso-S1 or meso-ZSM-5 were dried in a vacuum oven at $60{ }^{\circ} \mathrm{C}$ overnight and then impregnated to incipient wetness with an aqueous solution of either $\mathrm{Ni}\left(\mathrm{NO}_{3}\right)_{2}$ (for a $5 \mathrm{wt} \% \mathrm{Ni}$ zeolite) or $\mathrm{H}_{2} \mathrm{PtCl}_{6}$ solution (for a $1 \mathrm{wt} \%$ Pt zeolite). The impregnated samples were then dried at $80^{\circ} \mathrm{C}$ for $12 \mathrm{~h}$. The nickel-containing meso-ZSM-5 was calcined at $550{ }^{\circ} \mathrm{C}$ for $2 \mathrm{~h}$ to obtain $\mathrm{NiO}_{\mathrm{x}} /$ meso-ZSM-5, while the platinum-containing mesoS1 was first calcined at $350{ }^{\circ} \mathrm{C}$ for $2 \mathrm{~h}$ with a $0.5{ }^{\circ} \mathrm{C} / \mathrm{min}$ ramp in a muffle oven to achieve $\mathrm{PtO}_{\mathrm{x}} /$ meso-S1. The metal oxide-containing sample was then subjected to steam-assisted recrystallization to grow a shell around the $\mathrm{NiO}_{\mathrm{x}} /$ meso-ZSM-5 or $\mathrm{PtO}_{\mathrm{x}} / \mathrm{meso}-\mathrm{S} 1$. The shell was grown according to the procedure described above using $0.5 \mathrm{~g}$ zeolite, $1.8 \mathrm{~mL}$ TPAOH and 1.1 $\mathrm{mL}$ TEOS. The calcination was limited to $4 \mathrm{~h}$ calcination at $550^{\circ} \mathrm{C}$. The calcined Ni-containing zeolite was reduced under $10 \% \mathrm{H}_{2}$ in $\mathrm{N}_{2}$ at $750{ }^{\circ} \mathrm{C}$ for $2 \mathrm{~h}$ with a $5{ }^{\circ} \mathrm{C} / \mathrm{min}$ ramp to obtain 
Ni@recryst-ZSM-5(I). The calcined Pt zeolite was reduced under hydrogen at $600{ }^{\circ} \mathrm{C}$ for $3 \mathrm{~h}$ with a $5{ }^{\circ} \mathrm{C} / \mathrm{min}$ ramp to obtain Pt@recryst-S1(I). For encapsulation of Ni and Pt in meso-ZSM-5 and meso-S1, respectively, the $\mathrm{Ni}$ was reduced under $10 \% \mathrm{H}_{2}$ in $\mathrm{N}_{2}$ at $500{ }^{\circ} \mathrm{C}$ for $2 \mathrm{~h}$ with $5{ }^{\circ} \mathrm{C} / \mathrm{min}$ ramp after impregnation and drying at $80^{\circ} \mathrm{C}$ to obtain $\mathrm{Ni} /$ meso-ZSM-5 while Pt was reduced under hydrogen at $600{ }^{\circ} \mathrm{C}$ for $3 \mathrm{~h}$ with $5^{\circ} \mathrm{C} / \mathrm{min}$ ramp after calcination at $350{ }^{\circ} \mathrm{C}$ to obtain $\mathrm{Pt} / \mathrm{meso}-\mathrm{S} 1$.

Encapsulation of metals (approach II): The recryst-S1 and recryst-ZSM-5 zeolite were impregnated with $\mathrm{H}_{2} \mathrm{PtCl}_{6}$ and $\mathrm{Ni}\left(\mathrm{NO}_{3}\right)_{2}$ solution, respectively, to incipient wetness after drying in a vacuum oven at $60{ }^{\circ} \mathrm{C}$ overnight. Afterward the samples were dried at $80{ }^{\circ} \mathrm{C}$ for $12 \mathrm{~h}$. The Ni sample was reduced under $10 \% \mathrm{H}_{2}$ in $\mathrm{N}_{2}$ at $500{ }^{\circ} \mathrm{C}$ for $2 \mathrm{~h}$ with a $5{ }^{\circ} \mathrm{C} / \mathrm{min}$ ramp to obtain Ni@recryst-ZSM-5(II). The platinum-containing zeolite was first calcined at $350{ }^{\circ} \mathrm{C}$ for $2 \mathrm{~h}$ with a $0.5^{\circ} \mathrm{C} / \mathrm{min}$ ramp in a muffle oven (PtO ${ }_{\mathrm{x}} @$ recryst-S1(II)) and then reduced under hydrogen at $600{ }^{\circ} \mathrm{C}$ for $3 \mathrm{~h}$ with $5^{\circ} \mathrm{C} / \mathrm{min}$ ramp to obtain Pt@recryst-S1(II).

\section{Results and discussion}

Figure 2, Table 1, and Figure S1-S5 compiles the results from $\mathrm{N}_{2}$ physisorption and X-ray powder diffractions (XRPD) analysis of all the prepared support materials. In particular, the table shows the effect on the surface area and porosity by changing the ratio of TPAOH and TEOS during the steam-assisted recrystallization of the carbon templated mesoporous zeolites. In general, the addition of TEOS slightly decreased the total pore volume, while the surface area and micropore volume remained in the same range under all conditions. A significant increase in surface area and 
micropore volume was observed by the addition of large amounts of both TPAOH and TEOS in Entry 5.

Table 1. Outline of the prepared zeolites, the synthesis conditions and the results from $\mathrm{N}_{2}$ physisorption analysis.

\begin{tabular}{|c|c|c|c|c|c|c|}
\hline \# & Sample & TPAOH $^{\mathbf{a}}$ & TEOS $^{\mathbf{b}}$ & $\begin{array}{l}\text { Surface areac } \\
\left(\mathrm{m}^{2} / \mathrm{g}\right)\end{array}$ & $\begin{array}{l}\text { Pore volume } \\
\quad\left(\mathrm{cm}^{3} / \mathrm{g}\right)\end{array}$ & $\begin{array}{c}\text { Micropore volume } \\
\left(\mathrm{cm}^{3} / \mathrm{g}\right)\end{array}$ \\
\hline 1 & meso-S1 & - & - & 453 & 0.35 & 0.14 \\
\hline 2 & recryst-S1(1:0) & 1 & - & 449 & 0.32 & 0.13 \\
\hline 3 & recryst-S1 (1:1) & 1 & 1 & 422 & 0.30 & 0.13 \\
\hline 4 & recryst-S1 (2:0) & 2 & - & 451 & 0.33 & 0.12 \\
\hline 5 & recryst-S1 (2:2) & 2 & 2 & 530 & 0.30 & 0.16 \\
\hline 6 & meso-ZSM-5 & - & - & 432 & 0.30 & 0.13 \\
\hline 7 & recryst-ZSM-5 & 1 & 1 & 440 & 0.31 & 0.09 \\
\hline
\end{tabular}

[a] $1=3.6 \mathrm{~mL}$ and $2=7.2 \mathrm{~mL} 1 \mathrm{M}$ TPAOH to $1 \mathrm{~g}$ of meso-S1/meso-ZSM-5 [b] $1=2.3 \mathrm{~mL}$ and $2=4.6$ $\mathrm{mL}$ TEOS to $1 \mathrm{~g}$ of meso-S1/meso-ZSM-5 [c] calculated by the BET method [d] calculated at relative pressure $\mathrm{p} / \mathrm{p}_{0}=0.95[\mathrm{e}]$ calculated by the $t$-plot method.

More detailed information about the morphology of the recrystallized zeolites is evident from the physisorption isotherms and the pore size distributions shown for meso-S1, recryst-S1(1:0) and recryst-S1(1:1) in Figure 2A and Figure S2, respectively. 

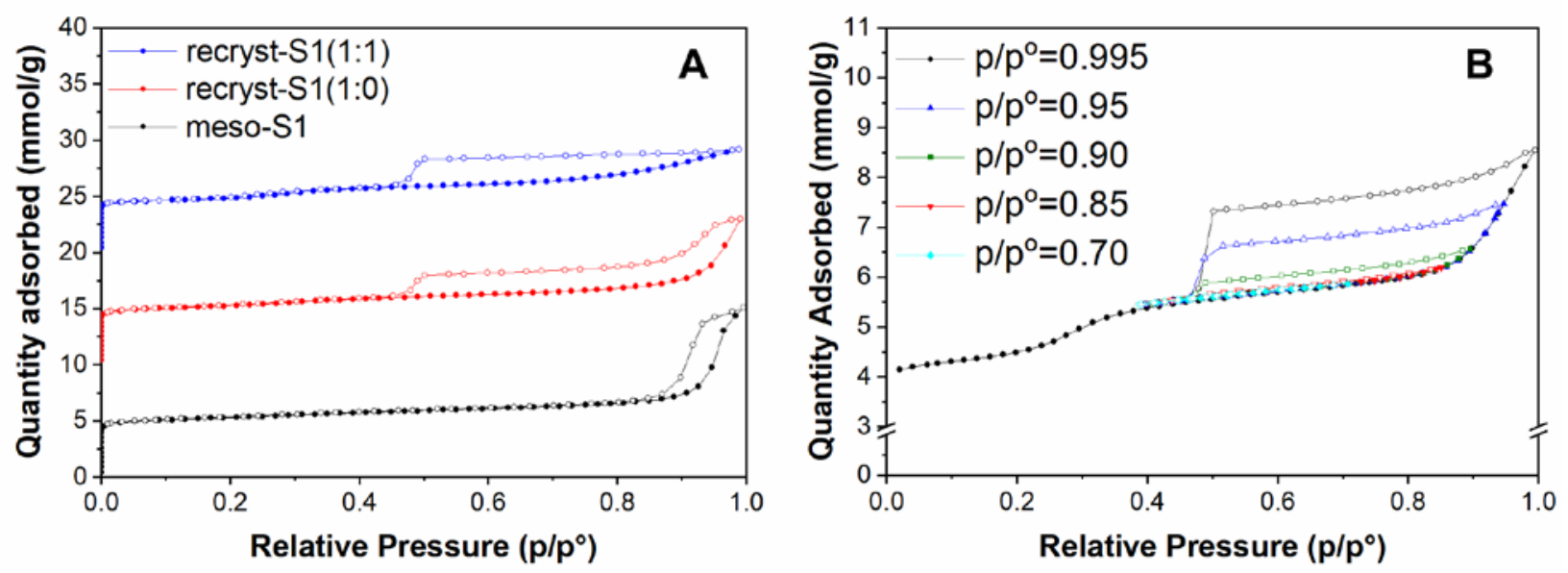

Figure 2. A) $\mathrm{N}_{2}$ physisorption isotherms of meso-S1 (black), recryst-S1(1:0) (red) and recrystS1(1:1) (blue) and B) hysteresis scan of recryst-S1(1:1)

As expected, the physisorption isotherms of all zeolites in Figure 2A show significant adsorption of $\mathrm{N}_{2}$ at low relative pressures $\left(\mathrm{p} / \mathrm{p}^{\circ}<0.01\right)$ which is typical for microporous zeolites. Furthermore, all three isotherms show a significant hysteresis loop at higher relative pressures. For meso-S1 (black), the hysteresis loop closes at around $\mathrm{p} / \mathrm{p}^{\circ}=0.85$, which indicates the presence of large and open mesopores $^{52,53}$. According to the IUPAC classification ${ }^{54}$, the physisorption isotherm of mesoS1 is a type IV with an H1 hysteresis loop. Figure S2 shows the corresponding pore size distribution as calculated by $\mathrm{BJH}$ analysis of the desorption branch and shows that the carbon templating result in a broad distribution of mesopores around between 10-34 nm in diameter. This result is in good agreement with previous reports ${ }^{29,55}$. In contrast, the hysteresis loops of recrystS1(1:0) and recryst-S1(1:1) (red and blue, respectively) modified by steam-assisted recrystallization are almost parallel until the forced closure point at around $\mathrm{p} / \mathrm{p}^{\circ}=0.45$. According to the IUPAC classification, these data correspond to type IV isotherms with type H2a hysteresis loops. This behavior indicates that the recrystallized zeolites have an inkbottle type porosity with a constricted system of internal voids and mesopores that are only accessible via the inherent 
zeolite micropores. ${ }^{53,56}$ It is important to mention that the peaks around $3.8 \mathrm{~nm}$ in the pore size distribution are not related to actual mesopores, but simply caused by cavitation and the so-called tensile strength effect at the forced closure point. ${ }^{57,58}$ As expected, the same peaks are not evident from the corresponding pore size distribution as calculated from the adsorption branch (data not shown). While the change from type $\mathrm{H} 1$ to type H2a hysteresis loops indicate the successful synthesis of a microporous zeolite shell, the physisorption analysis also reveals that both TPAOH and TEOS are required to transform all open mesopores into fully enclosed compartments. While recryst-S1(1:0) has a total pore volume of $0.32 \mathrm{~g} / \mathrm{cm}^{3}$ and BJH analysis indicates some remaining open porosity in the mesoporous range, recryst-S1(1:1) has a total pore volume of $0.30 \mathrm{~g} / \mathrm{cm}^{3}$ and a relatively flat desorption branch until the forced closure point at $\mathrm{p} / \mathrm{p}^{\circ}=0.45$. Figure $2 \mathrm{~B}$ shows the isotherms from a hysteresis scanning experiment performed on recryst-S1(1:1) to investigate the desorption branches at different partial pressures and degrees of filling in more detail. As expected, the flat shape of the desorption scans confirm that all the mesopores empty via cavitation controlled evaporation rather than pore blocking. ${ }^{52,59,60}$

Figure S1 shows the XRPD analysis of meso-S1, recryst-S1(1:0) and recryst-S1(1:1), respectively. The diffraction patterns of all other zeolite materials are shown in Figure S3. In general, the diffraction patterns show no significant differences between the parent and modified zeolites. This confirms that both carbon templating and steam-assisted recrystallization result in zeolites with the expected MFI structure and good crystallinity. ${ }^{61}$ Furthermore, the diffraction patterns show no significant differences between the recrystallized samples prepared with different ratios of zeolite, TPAOH and TEOS, which is in good agreement with the results from $\mathrm{N}_{2}$ physisorption analysis reported in Table 1. 
Figure 3 shows an SEM and TEM image of meso-S1 and recryst-S1(1:1), respectively. The SEM images show that the crystal size of both samples is around 1-2 $\mu \mathrm{m}$, which confirms that the added TEOS crystallizes on the surface of the carbon templated zeolites rather than in new separate crystals. We therefore speculate that the carbon templated zeolite may function as effective seed crystals in this step. Furthermore, the SEM images show a significant difference in the surface features of the two samples. While the surface of meso-S1 appears fluffy, which is typical for mesoporous zeolites and in good agreement with previous reports, ${ }^{13,19,62,63}$ the surface of recrystS1(1:1) appears more smooth with well-defined terraces. The same features are also evident from the TEM images, which also reveal more insight into the nature of the enclosed mesopores. While Figure 3C clearly shows the open porosity of the carbon-templated zeolite, Figure 3D exhibits how the steam-assisted crystallization has restructured the surface of the zeolite and transformed the open porosity into a large number of small and separate compartments. The thickness of the zeolite shell is typically in the range of $10-30 \mathrm{~nm}$.
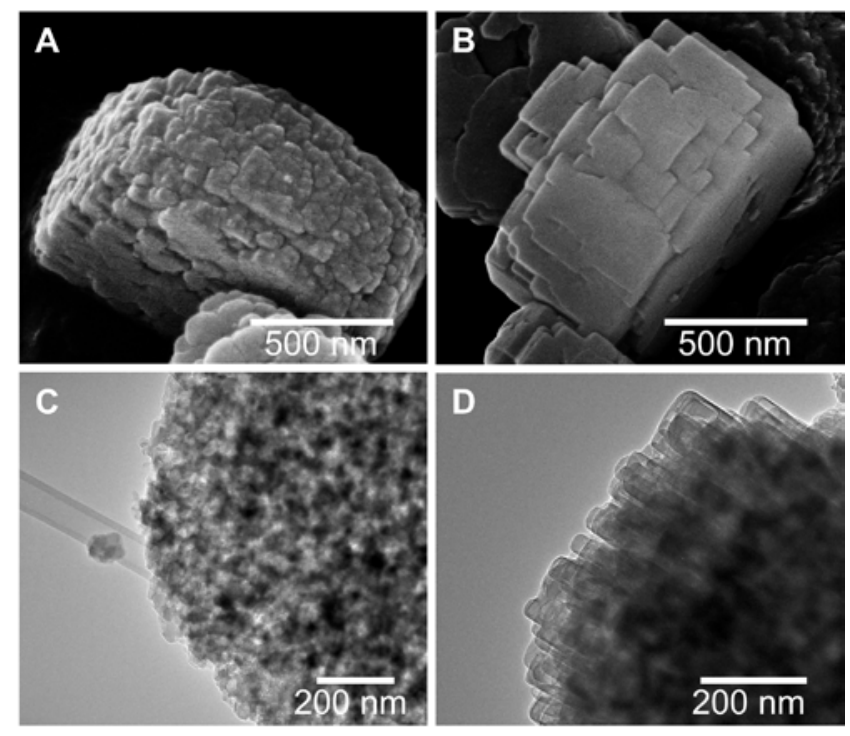

Figure 3. SEM and TEM images of meso-S1 (A+C) and recryst-S1(1:1) (B+D) 
Based on our previous experience with encapsulated metal nanoparticles, we speculated if the steam-assisted recrystallization could offer a general method to encapsulate both base and noble metal nanoparticles in mesoporous zeolites. We therefore prepared a number of $\mathrm{Ni}$ and Pt catalysts by simple impregnation of the metal precursors on the mesoporous zeolites both before and after the steam-assisted recrystallization.

Figure 4 shows the TEM images of the Ni catalysts together with their corresponding particle size histogram fitted with a log-normal distribution. For comparison, Ni/meso-ZSM-5 was prepared by impregnation of carbon-templated meso-ZSM-5, Ni@recryst-ZSM-5(I) was prepared by impregnation of carbon-templated meso-ZSM-5 followed by steam-assisted recrystallization and Ni@recryst-ZSM-5(II) was prepared by steam-assisted recrystallization of meso-ZSM-5 followed by impregnation. The nickel-containing catalysts were reduced under the as-mentioned conditions (please see experimental section).

The first TEM image in Figure 4 shows that a number of large Ni nanoparticles (up to $46 \mathrm{~nm}$ ) were present on the external surface of Ni/meso-ZSM-5, which resulted in a relatively broad particle size distribution. In contrast, less $\mathrm{Ni}$ nanoparticles were present on the external surface area of Ni@recryst-ZSM-5(I) and Ni@recryst-ZSM-5(II), which resulted in smaller nanoparticles and more narrow size distributions. Furthermore, the TEM images also show that the enclosed porosity appeared to encapsulate a significant number of the Ni nanoparticles within the zeolite shell. The XRPD patterns of the three Ni catalysts are shown in Figure S6 in the supporting information. Besides the characteristic diffraction pattern of ZSM-5, the XRD analysis also reveal some small peaks from $\mathrm{Ni}(111)$. Although the signals are too weak to confirm the average particle size by line broadening analysis, the results indicate that the Ni nanoparticles decrease in the order of Ni/meso-ZSM-5>Ni@recryst-ZSM-5(II)>Ni@recryst-ZSM-5(I). 

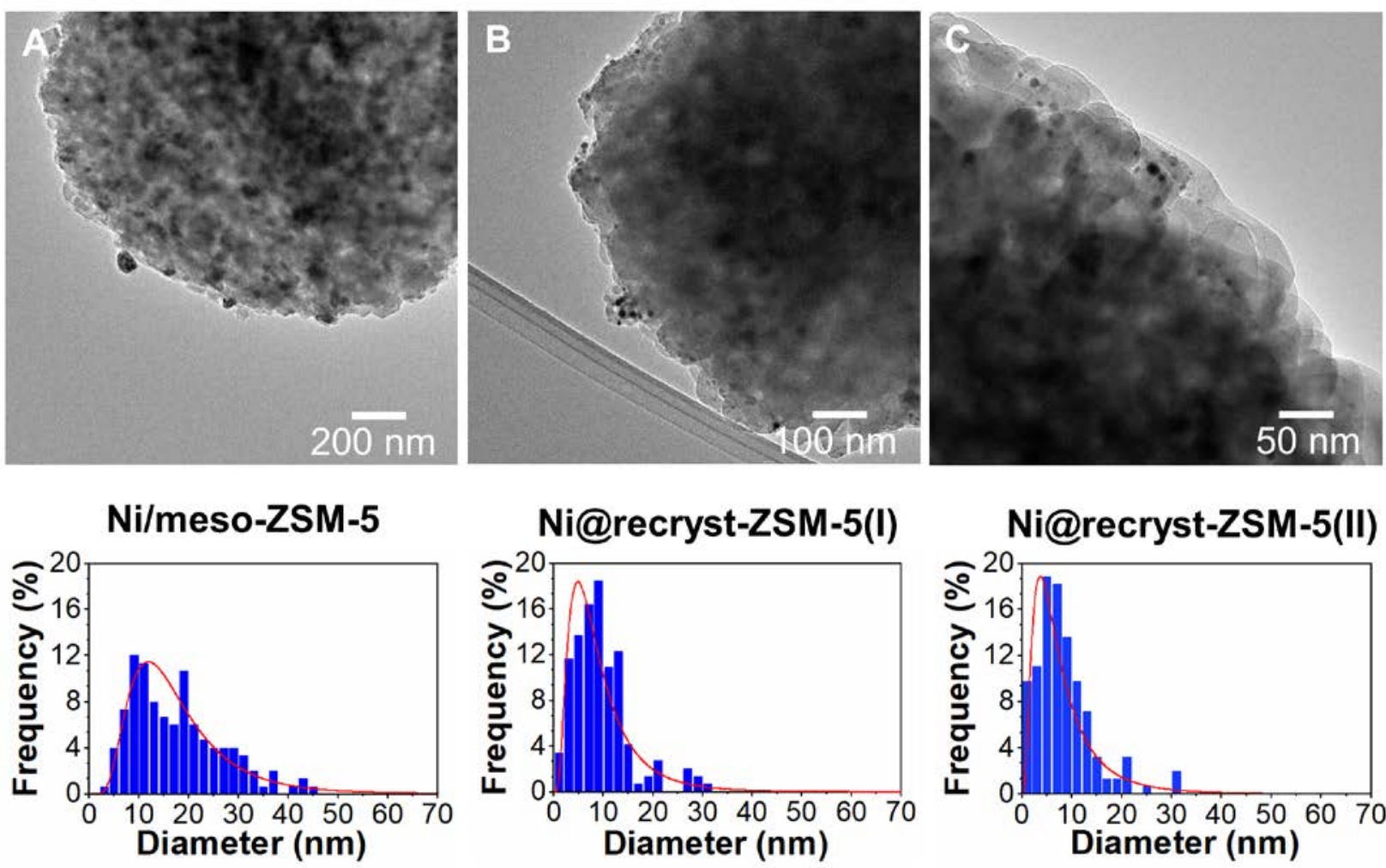

Figure 4. TEM images of A) Ni/meso-ZSM-5, B) Ni@recryst-ZSM-5(I) and C) Ni@recrystZSM-5(II) together with their particle size distributions based on the measurement of $>100$ nanoparticles.

In order to compare the catalytic activity, we tested the Ni catalysts for high-temperature $\mathrm{CO}_{2}$ methanation, which is an important reaction that is well known to suffer from sintering. ${ }^{64-66}$ Figure $5 \mathrm{~A}, \mathrm{~B}$, and $\mathrm{C}$ show the molar fraction of $\mathrm{CH}_{4}, \mathrm{CO}$ and $\mathrm{CO}_{2}$ as a function of the reaction temperature. A comparison of the product distribution at $450{ }^{\circ} \mathrm{C}$ shows that Ni@recryst-ZSM5(II) results in 49\% conversion and 93\% selectivity, which is significantly higher than the other catalysts. Considering the similar particle size distributions of Ni@recryst-ZSM-5(II) and Ni@recryst-ZSM-5(I), we speculate that the alkaline and hydrothermal conditions under the steam-assisted recrystallization could result in the formation of nickel phyllosilicates 
(see Figure S10). It has previously been shown that these phyllosilicates are difficult to reduce into Ni nanoparticles and may decrease the catalytic activity. ${ }^{6,42}$ Approach II (post-impregnation) does not suffer from the formation of these inactive species and is therefore the most effective method to encapsulate base metals such as Ni nanoparticles.
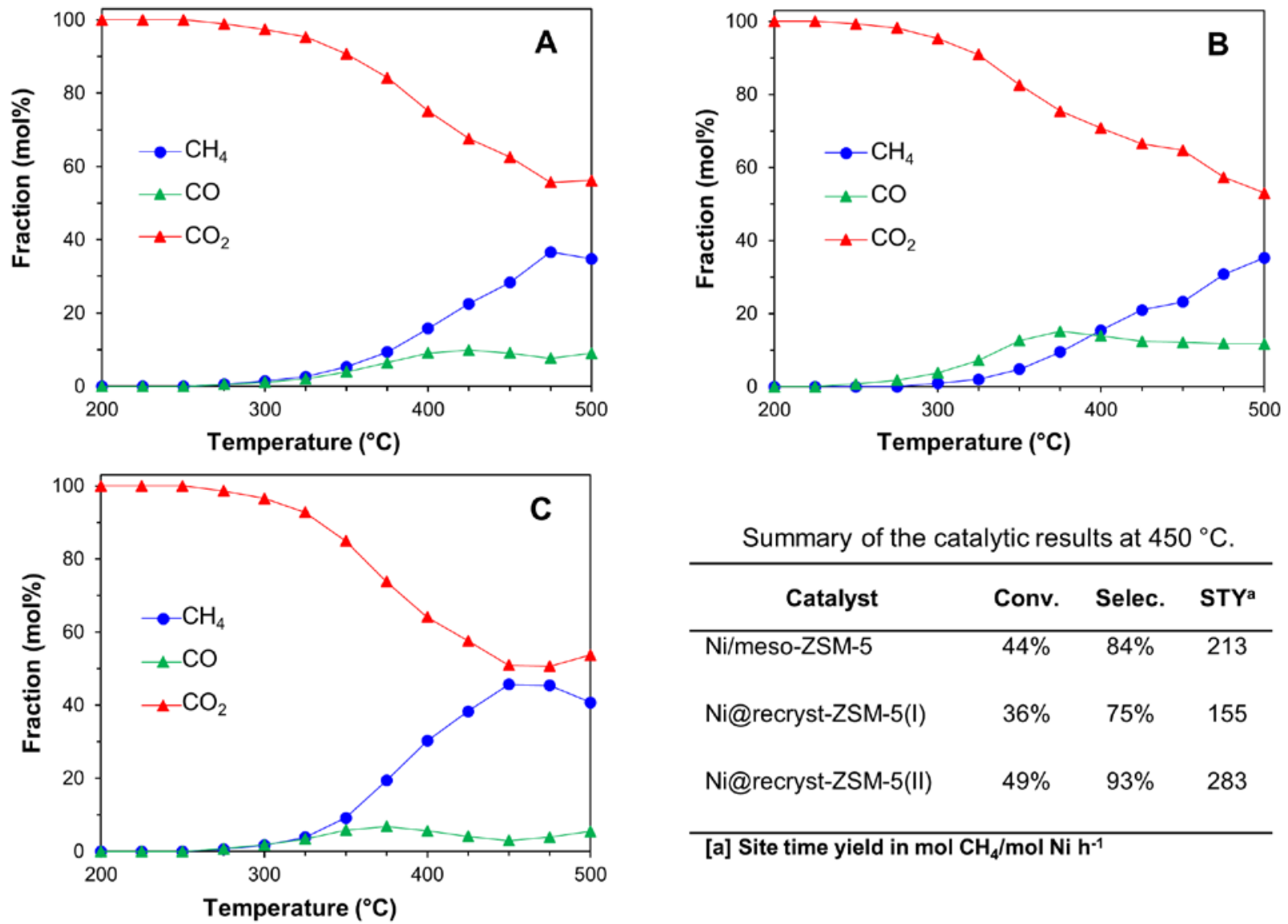

Summary of the catalytic results at $450^{\circ} \mathrm{C}$.

\begin{tabular}{lccc}
\hline \multicolumn{1}{c}{ Catalyst } & Conv. & Selec. & STYa \\
\hline Ni/meso-ZSM-5 & $44 \%$ & $84 \%$ & 213 \\
Ni@recryst-ZSM-5(I) & $36 \%$ & $75 \%$ & 155 \\
Ni@recryst-ZSM-5(II) & $49 \%$ & $93 \%$ & 283 \\
& & & \\
\hline [a] Site time yield in $\mathrm{mol} \mathrm{CH}_{4} / \mathrm{mol} \mathrm{Ni} \mathrm{h}^{-1}$
\end{tabular}

Figure 5. Product distribution as a function of the temperature for A) Ni/meso-ZSM-5, B) Ni@recryst-ZSM-5(I) and C) Ni@recryst-ZSM-5(II) together with a summary of the catalytic activity at $450{ }^{\circ} \mathrm{C}$. 
Figure 6 shows the catalytic activity of Ni/meso-ZSM-5 compared to Ni@recryst-ZSM-5(II) over $50 \mathrm{~h}$ at $450{ }^{\circ} \mathrm{C}$. The results clearly show that Ni@recryst-ZSM-5(II) not only results in higher conversion and selectivity, but also in higher stability over time.
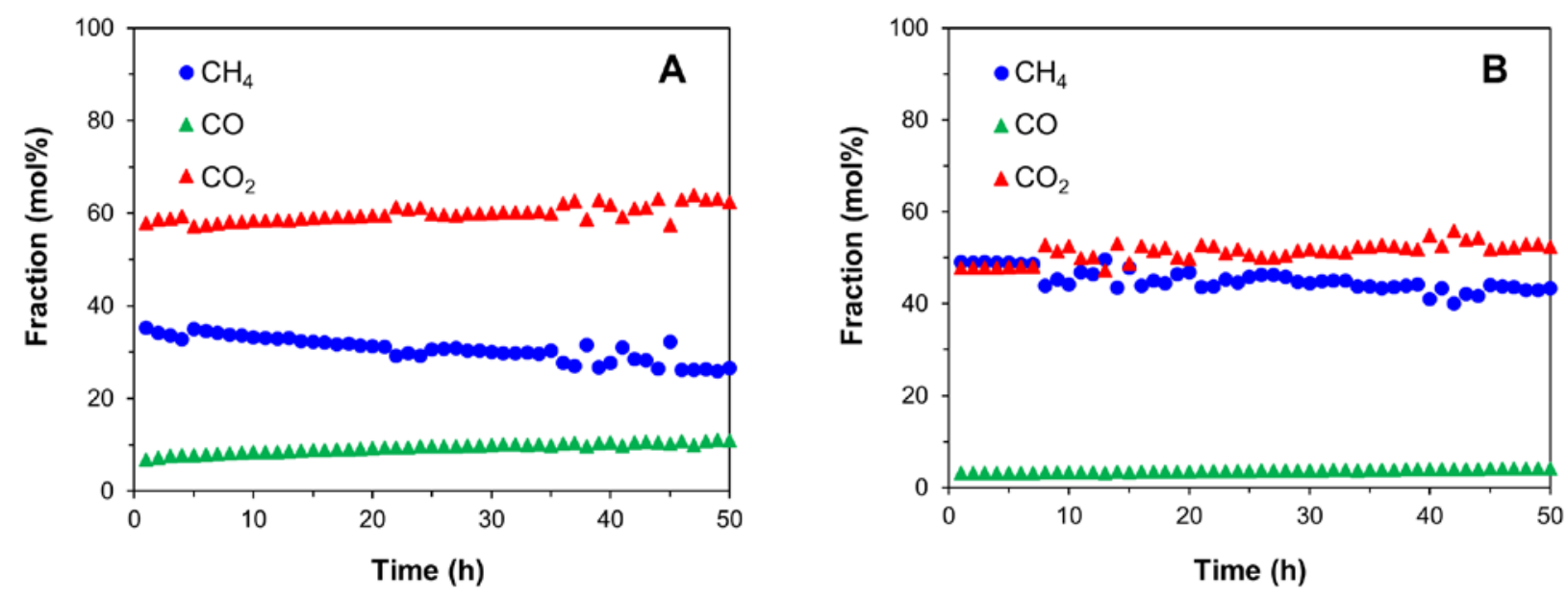

Figure 6. Catalytic stability for A) Ni/meso-ZSM-5 and B) Ni@recryst-ZSM-5(II) over 50 h at $450^{\circ} \mathrm{C}$.

Figure S12 shows the results from the TEM analysis of the spent catalysts after $50 \mathrm{~h}$ at $450{ }^{\circ} \mathrm{C}$. The TEM image of Ni/meso-ZSM-5 shows the formation of large Ni nanoparticles on the surface of the catalysts, which indicates that severe sintering may explain the poor stability. In contrast, the TEM image of Ni@recryst-ZSM-5 shows that the zeolite-encapsulated nanoparticles appear to remain within the confined space of the small zeolite compartments. This indicates that the zeolite shell effectively prevents nanoparticle migration and coalescence on the surface of the catalyst, which results in a higher metal dispersion, a higher catalytic activity and higher thermal stability. 
In order to investigate if noble metal nanoparticles could be encapsulated by impregnation of the carbon-templated zeolite prior to the steam-assisted recrystallization, we then prepared Pt/mesoS1 and Pt@recryst-S1(I). As expected, the XRPD analysis shows the characteristic diffraction pattern of the MFI zeolite as well as an additional peak from Pt(111) at 39.6 ${ }^{\circ}$, see Figure S15. Figure S17 shows the XPS analysis for the Pt 4f orbitals in Pt/meso-S1 and Pt@recryst-S1(I), respectively. The difference in signal intensity indicates that significantly more Pt is present on the surface of Pt/meso-S1 than on the surface of Pt@recryst-S1(I). For comparison, ICP-OES analysis showed that the metal loading of Pt/meso-S1 and Pt@recryst-S1(I) was 0.8\% and 0.7\%, respectively. Since the change in metal loading can only account for $12.5 \%$ of the decrease in signal intensity, we assign the rest of the decrease to a successful encapsulation of the Pt nanoparticles.

Figure 7 shows two representative STEM images of the Pt catalysts (please see Figure S18 and S19 for more images). With the exception of a few larger nanoparticles on the surface of the catalyst, the STEM analysis shows that a large number of small nanoparticles are still present on Pt@recryst-S1(I) after the steam-assisted recrystallization.
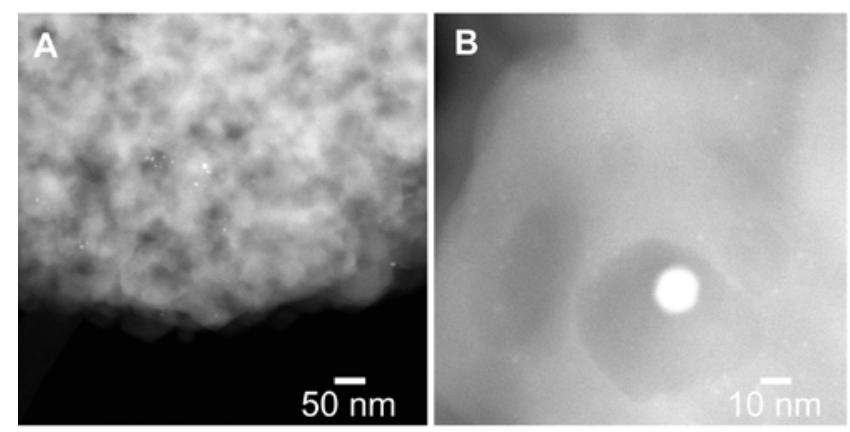

Figure 7: STEM images of Pt/meso-S1 (A) and Pt@recryst-S1(I) (B). 
In order to investigate the degree of encapsulation and the potential use for selective catalysis, we tested the two Pt catalysts for the shape-selective hydrogenation of linear and cyclic alkenes. The results in Table 2 clearly show that encapsulation of the Pt nanoparticles had a significant effect on the catalytic activity. As expected, the effect is most pronounced for cyclododecene, which is too large to enter the microporous zeolite. These results therefore confirm that the recrystallized zeolite encapsulates a large fraction of the Pt nanoparticles. For the two smaller molecules, 1-octene and cyclooctene, the decreased activity may be explained by a slower diffusion $^{5,48}$. In order to investigate the effect of the preparation procedure, we also tried to encapsulate the Pt nanoparticle after the steam-assisted recrystallization (Pt@recryst-S1(II)), please see supporting information. This, however, resulted in a significantly lower size selectivity (see Table S2), which indicates an incomplete encapsulation of the Pt nanoparticles (Figure S20). For this reason, it appears that Approach I (pre-impregnation) is the more effective method to encapsulate noble metals such as Pt nanoparticles.

Table 2. Catalytic results from the hydrogenation of alkenes ${ }^{\mathrm{a}}$

\begin{tabular}{lcccc}
\hline Catalyst & Substrate & Product & Time & Conversion \\
\hline \multirow{2}{*}{ Pt/meso-S1 } & oct-1ene & octane & $1 \mathrm{~h}$ & $99 \%$ \\
& cis-cyclooctene & cyclooctane & $1 \mathrm{~h}$ & $99 \%$ \\
& cyclododecene & cyclododecane & $24 \mathrm{~h}$ & $53 \%$ \\
\hline \multirow{2}{*}{ Pt@recryst-S1(I) } & oct-1ene & octane & $1 \mathrm{~h}$ & $6 \%$ \\
& cis-cyclooctene & cyclooctane & $1 \mathrm{~h}$ & $8 \%$ \\
& cis-cyclooctene & cyclooctane & $24 \mathrm{~h}$ & $79 \%$ \\
& cyclododecene & cyclododecane & $24 \mathrm{~h}$ & $1 \%$
\end{tabular}

[a] Reaction conditions: alkene (1 mmol), catalyst (50 mg), decane (internal standard, $0.2 \mathrm{mmol}$ ), ethyl acetate ( $5 \mathrm{~mL}$ ), 1 bar $\mathrm{H}_{2}$ room temperature [b] Conversion determined by GC-FID. 


\section{Conclusion}

A general steam-assisted recrystallization method was developed to encapsulate both base and noble metal nanoparticles inside the internal voids of compartmentalized mesoporous ZSM-5 or silicalite-1. For full coverage of mesoporous zeolite with a microporous layer, both TEOS and TPAOH were required. It was shown that encapsulated Ni nanoparticles, where Ni was introduced after steam-assisted recrystallizations (Approach II), was the most active and stable catalyst for $\mathrm{CO}_{2}$ methanation with a site time yield of $283 \mathrm{~mol} \mathrm{CH}_{4} / \mathrm{mol} \mathrm{Ni} \mathrm{h}^{-1}$. Whereas, the zeolite encapsulated Ni nanoparticles prepared according to approach I suffer from the possible formation of inactive nickel phyllosilicates. Approach II offers a suitable way to obtain sinter-stable encapsulated base metals which can be used for high temperature reactions.

Furthermore, it was demonstrated that the Pt catalyst prepared by introducing the Pt nanoparticles prior to the steam-assisted recrystallization (approach I), was more size-selective in linear and cyclic alkenes hydrogenation, and prove that the method is highly applicable for obtaining size selective catalysts. Therefore, we conclude that approach I is more effective for encapsulation of noble metals while approach II is more effective for encapsulation of base metals. The general method offers a new way for encapsulation of metals in hierarchical zeolite catalysts.

\section{ASSOCIATED CONTENT}

Supporting Information. Experimental characterization conditions, materials used for synthesis, reaction conditions and analysis for hydrogenation of alkenes and methanation, XRPD and $\mathrm{N}_{2}$ physisorption of samples for shell optimization, XRPD and TEM images of Ni zeolites 
before and after stability test, XRPD and STEM images of Pt zeolites, textural properties of

Pt@recryst-S1(II), XPS of Pt zeolites, catalytic results of Pt@recryst-S1(II) (PDF)

\section{AUTHOR INFORMATION}

Corresponding Author

E-mail: skk@kemi.dtu.dk, tel. +45 45252402

Email: jjmie@kemi.dtu.dk tel. +45 45252363

\section{Author Contributions}

The manuscript was written through contributions of all authors. All authors have given approval to the final version of the manuscript.

\section{Funding Sources}

The work has funding from the Independent Research Fund Denmark (grant no. 6111-00237), from Villum fonden (Grant No. 13158), and from Haldor Topsøe A/S.

\section{Notes}

The authors declare no competing financial interest.

\section{ACKNOWLEDGMENT}

We thank Haldor Topsøe A/S for doing ICP analysis. We acknowledge Diamond Light Source for time on electron Physical Science Imaging Centre under Proposal 20892 and 20650 and the support by Dr Mohsen Danaie and Dr Tom Slater during sessions. The authors are grateful for funding from the Independent Research Fund Denmark (grant no. 6111-00237), from Villum fonden (Grant No. 13158), and from Haldor Topsøe A/S. 


\section{REFERENCES}

(1) Čejka, J.; Mintova, S. Perspectives of Micro/Mesoporous Composites in Catalysis. Catal. Rev. - Sci. Eng. 2007, 49 (4), 457-509. https://doi.org/10.1080/01614940701583240.

(2) Davis, M. E.; Lobo, R. F. Zeolite and Molecular Sieve Synthesis. Chem. Mater. 1992, 4 (4), 756-768. https://doi.org/10.1021/cm00022a005.

(3) Corma, A. Inorganic Solid Acids and Their Use in Acid-Catalyzed Hydrocarbon Reactions. Chem. Rev. 1995, 95 (3), 559-614. https://doi.org/10.1021/cr00035a006.

(4) Saravanamurugan, S.; Tosi, I.; Rasmussen, K. H.; Jensen, R. E.; Taarning, E.; Meier, S.; Riisager, A. Facile and Benign Conversion of Sucrose to Fructose Using Zeolites with Balanced Brønsted and Lewis Acidity. Catal. Sci. Technol. 2017, 7 (13), 2782-2788. https://doi.org/10.1039/C7CY00540G.

(5) Goel, S.; Zones, S. I.; Iglesia, E. Encapsulation of Metal Clusters within MFI via Interzeolite Transformations and Direct Hydrothermal Syntheses and Catalytic Consequences of Their Confinement. J. Am. Chem. Soc. 2014, 136 (43), 15280-15290. https://doi.org/10.1021/ja507956m.

(6) Li, S.; Tuel, A.; Laprune, D.; Meunier, F.; Farrusseng, D. Transition-Metal Nanoparticles in Hollow Zeolite Single Crystals as Bifunctional and Size-Selective Hydrogenation Catalysts. Chem. Mater. 2015, 27 (1), 276-282. https://doi.org/10.1021/cm503921f.

(7) Mielby, J.; Abildstrøm, J. O.; Wang, F.; Kasama, T.; Weidenthaler, C.; Kegnaes, S. Oxidation of Bioethanol Using Zeolite-Encapsulated Gold Nanoparticles. Angew. Chemie 
Int. Ed. 2014, 53 (46), 12513-12516. https://doi.org/10.1002/anie.201406354.

(8) Cui, T.-L.; Ke, W.-Y.; Zhang, W.-B.; Wang, H.-H.; Li, X.-H.; Chen, J.-S. Encapsulating Palladium Nanoparticles Inside Mesoporous MFI Zeolite Nanocrystals for Shape-Selective Catalysis. Angew. Chemie Int. Ed. 2016, 55 (32), 9178-9182. https://doi.org/10.1002/anie.201602429.

(9) Zhang, J.; Wang, L.; Zhu, L.; Wu, Q.; Chen, C.; Wang, X.; Ji, Y.; Meng, X.; Xiao, F.-S. Solvent-Free Synthesis of Zeolite Crystals Encapsulating Gold-Palladium Nanoparticles for the Selective Oxidation of Bioethanol. ChemSusChem 2015, 8 (17), 2867-2871. https://doi.org/10.1002/cssc.201500261.

(10) Laursen, A. B.; Højholt, K. T.; Lundegaard, L. F.; Simonsen, S. B.; Helveg, S.; Schüth, F.; Paul, M.; Grunwaldt, J.-D.; Kegnaes, S.; Christensen, C. H.; Egeblad, K. Substrate SizeSelective Catalysis with Zeolite-Encapsulated Gold Nanoparticles. Angew. Chemie 2010, 122 (20), 3582-3585. https://doi.org/10.1002/ange.200906977.

(11) Miyake, K.; Inoue, R.; Nakai, M.; Hirota, Y.; Uchida, Y.; Tanaka, S.; Miyamoto, M.; Nishiyama, N. Fabrication of Pt Nanoparticles Encapsulated in Single Crystal like Silicalite1 Zeolite as a Catalyst for Shape-Selective Hydrogenation of C6 Olefins. Microporous Mesoporous $\quad$ Mater. 2018, 271, 156-159. https://doi.org/10.1016/J.MICROMESO.2018.05.051.

(12) Goel, S.; Wu, Z.; Zones, S. I.; Iglesia, E. Synthesis and Catalytic Properties of Metal Clusters Encapsulated within Small-Pore (SOD, GIS, ANA) Zeolites. J. Am. Chem. Soc. 2012, 134 (42), 17688-17695. https://doi.org/10.1021/ja307370z. 
(13) Farrusseng, D.; Tuel, A. Perspectives on Zeolite-Encapsulated Metal Nanoparticles and Their Applications in Catalysis. New J. Chem. 2016, 40 (5), 3933-3949. https://doi.org/10.1039/c5nj02608c.

(14) Højholt, K. T.; Laursen, A. B.; Kegnæs, S.; Christensen, C. H. Size-Selective Oxidation of Aldehydes with Zeolite Encapsulated Gold Nanoparticles. Top. Catal. 2011, 54 (16-18), 1026-1033. https://doi.org/10.1007/s11244-011-9722-x.

(15) Goodarzi, F.; Kang, L.; Wang, F. R.; Joensen, F.; Kegnæs, S.; Mielby, J. Methanation of Carbon Dioxide over Zeolite-Encapsulated Nickel Nanoparticles. ChemCatChem 2018, 10 (7). https://doi.org/10.1002/cctc.201701946.

(16) Christensen, C. H.; Johannsen, K.; Törnqvist, E.; Schmidt, I.; Topsøe, H.; Christensen, C. H. Mesoporous Zeolite Single Crystal Catalysts: Diffusion and Catalysis in Hierarchical Zeolites. Catal. Today 2007, 128 (3-4 SPEC. ISS.), 117-122. https://doi.org/10.1016/j.cattod.2007.06.082.

(17) Jiang, J.; Jorda, J. L.; Yu, J.; Baumes, L. A.; Mugnaioli, E.; Diaz-Cabanas, M. J.; Kolb, U.; Corma, A. Synthesis and Structure Determination of the Hierarchical Meso-Microporous Zeolite ITQ-43. Science (80-. $\quad$ ). $\quad$ 2011, $333 \quad$ (6046), 1131-1134. https://doi.org/10.1126/science.1208652.

(18) Tosheva, L.; Valtchev, V. P. Nanozeolites: Synthesis, Crystallization Mechanism, and Applications. Chem. Mater. 2005, 17 (10), 2494-2513. https://doi.org/10.1021/cm047908z.

(19) Pérez-Ramírez, J.; Christensen, C. H.; Egeblad, K.; Christensen, C. H.; Groen, J. C. Hierarchical Zeolites: Enhanced Utilisation of Microporous Crystals in Catalysis by 
Advances in Materials Design. Chem. Soc. Rev. 2008, 37 (11), 2530. https://doi.org/10.1039/b809030k.

(20) K. Egeblad, C. H. Christensen, M. Kustova, C. H. C. Templating Mesoporous Zeolites. Chem. Mater. 2008, 20, 946.

(21) Ivanova, I. I.; Knyazeva, E. E. Micro-Mesoporous Materials Obtained by Zeoliterecrystallization: Synthesis, Characterization and Catalytic Applications. Chem. Soc. Rev. 2013, 42 (9), 3671-3688. https://doi.org/10.1039/C2CS35341E.

(22) Abildstrøm, J. O.; Ali, Z. N.; Mentzel, U. V.; Mielby, J.; Kegnæs, S.; Kegnæs, M. Mesoporous MEL, BEA, and FAU Zeolite Crystals Obtained by in Situ Formation of Carbon Template over Metal Nanoparticles. New J. Chem. 2016, 40 (5), 4223-4227. https://doi.org/10.1039/C5NJ02809D.

(23) Janssen, A. H.; Koster, A. J.; de Jong, K. P. Three-Dimensional Transmission Electron Microscopic Observations of Mesopores in Dealuminated Zeolite Y. Angew. Chemie Int. $\begin{array}{lllll}\text { Ed. 2001, } & 40 & \text { (6), } & 1102-1104 . \quad \text { https://doi.org/10.1002/1521- }\end{array}$ 3773(20010316)40:6<1102::AID-ANIE11020>3.0.CO;2-6.

(24) Choifeng, C.; Hall, J. B.; Huggins, B. J.; Beyerlein, R. A. Electron Microscope Investigation of Mesopore Formation and Aluminum Migration in USY Catalysts. J. Catal. 1993, 140 (2), 395-405. https://doi.org/10.1006/jcat.1993.1093.

(25) Ivanova, I. I.; Kuznetsov, A. S.; Ponomareva, O. A.; Yuschenko, V. V.; Knyazeva, E. E. Micro/Mesoporous Catalysts Obtained by Recrystallization of Mordenite. Stud. Surf. Sci. Catal. 2005, 158, 121-128. https://doi.org/10.1016/S0167-2991(05)80330-1. 
(26) Chal, R.; Cacciaguerra, T.; van Donk, S.; Gérardin, C. Pseudomorphic Synthesis of Mesoporous Zeolite Y Crystals. Chem. Commun. 2010, 46 (41), 7840. https://doi.org/10.1039/c0cc02073g.

(27) Peréz-Ramírez, J.; Verboekend, D.; Bonilla, A.; Abelló, S. Zeolite Catalysts with Tunable Hierarchy Factor by Pore-Growth Moderators. Adv. Funct. Mater. 2009, 19 (24), 39723979. https://doi.org/10.1002/adfm.200901394.

(28) Schmidt, I.; Boisen, A.; Gustavsson, E.; Ståhl, K.; Pehrson, S.; Dahl, S.; Carlsson, A.; Jacobsen, C. J. H. Carbon Nanotube Templated Growth of Mesoporous Zeolite Single Crystals. Chem. Mater. 2001, 13 (12), 4416-4418. https://doi.org/10.1021/cm011206h.

(29) Jacobsen, C. J. H.; Madsen, C.; Houzvicka, J.; Schmidt, I.; Carlsson, A. Mesoporous Zeolite Single Crystals. J. Am. Chem. Soc. 2000, $122 \quad$ (29), 7116-7117. https://doi.org/10.1021/ja000744c.

(30) Han, S.; Wang, Z.; Meng, L.; Jiang, N. Synthesis of Uniform Mesoporous ZSM-5 Using Hydrophilic Carbon as a Hard Template. Mater. Chem. Phys. 2016, 177, 112-117. https://doi.org/10.1016/j.matchemphys.2016.04.003.

(31) Zhang, Y.; Okubo, T.; OguraPresent address: Institute of, M. Synthesis of Mesoporous Aluminosilicate with Zeolitic Characteristics Using Vapor Phase Transport. Chem. Commun. 2005, No. 21, 2719. https://doi.org/10.1039/b500075k.

(32) Abildstrøm, J. O.; Kegnæs, M.; Hytoft, G.; Mielby, J.; Kegnæs, S. Synthesis of Mesoporous Zeolite Catalysts by in Situ Formation of Carbon Template over Nickel Nanoparticles. Microporous Mesoporous $\quad$ Mater. 2016, 232-237. 
https://doi.org/10.1016/j.micromeso.2015.12.015.

(33) Liu, F.; Willhammar, T.; Wang, L.; Zhu, L.; Sun, Q.; Meng, X.; Carrillo-Cabrera, W.; Zou, X.; Xiao, F. S. ZSM-5 Zeolite Single Crystals with b-Axis-Aligned Mesoporous Channels as an Efficient Catalyst for Conversion of Bulky Organic Molecules. J. Am. Chem. Soc. 2012, 134 (10), 4557-4560. https://doi.org/10.1021/ja300078q.

(34) Wang, L.; Zhang, Z.; Yin, C.; Shan, Z.; Xiao, F.-S. Hierarchical Mesoporous Zeolites with Controllable Mesoporosity Templated from Cationic Polymers. Microporous Mesoporous Mater. 2010, 131 (1-3), 58-67. https://doi.org/10.1016/J.MICROMESO.2009.12.001.

(35) Xiao, F.-S.; Wang, L.; Yin, C.; Lin, K.; Di, Y.; Li, J.; Xu, R.; Su, D. S.; Schlögl, R.; Yokoi, T.; Tatsumi, T. Catalytic Properties of Hierarchical Mesoporous Zeolites Templated with a Mixture of Small Organic Ammonium Salts and Mesoscale Cationic Polymers. Angew. Chemie Int. Ed. 2006, 45 (19), 3090-3093. https://doi.org/10.1002/anie.200600241.

(36) Wang, H.; Pinnavaia, T. J. MFI Zeolite with Small and Uniform Intracrystal Mesopores. Angew. Chemie Int. Ed. 2006, 45 (45), 7603-7606. https://doi.org/10.1002/anie.200602595.

(37) Wang, N.; Sun, Q.; Bai, R.; Li, X.; Guo, G.; Yu, J. In Situ Confinement of Ultrasmall Pd Clusters within Nanosized Silicalite-1 Zeolite for Highly Efficient Catalysis of Hydrogen Generation. J. Am. Chem. Soc. 2016, 138 (24), 7484-7487.

(38) Moliner, M.; Gabay, J. E.; Kliewer, C. E.; Carr, R. T.; Guzman, J.; Casty, G. L.; Serna, P.; Corma, A. Reversible Transformation of Pt Nanoparticles into Single Atoms inside HighSilica Chabazite Zeolite. J. Am. Chem. Soc. 2016, 138 (48), 15743-15750. https://doi.org/10.1021/jacs.6b10169. 
(39) Zhang, Y.; Kubů, M.; Mazur, M.; Čejka, J. Encapsulation of Pt Nanoparticles into IPC-2 and IPC-4 Zeolites Using the ADOR Approach. Microporous Mesoporous Mater. 2019, 279, 364-370. https://doi.org/10.1016/J.MICROMESO.2019.01.018.

(40) Liu, L.; Díaz, U.; Arenal, R.; Agostini, G.; Concepción, P.; Corma, A. Generation of Subnanometric Platinum with High Stability during Transformation of a 2D Zeolite into 3D. Nat. Mater. 2017, 16 (1), 132-138. https://doi.org/10.1038/nmat4757.

(41) Kim, J. C.; Lee, S.; Cho, K.; Na, K.; Lee, C.; Ryoo, R. Mesoporous MFI Zeolite Nanosponge Supporting Cobalt Nanoparticles as a Fischer-Tropsch Catalyst with High Yield of Branched Hydrocarbons in the Gasoline Range. ACS Catal. 2014, 4 (11), 39193927. https://doi.org/10.1021/cs500784v.

(42) Laprune, D.; Tuel, A.; Farrusseng, D.; Meunier, F. Highly Dispersed Nickel Particles Encapsulated in Multi-Hollow Silicalite-1 Single Crystals - Effects of Siliceous Deposits and Phosphorous Species on the Catalytic Performances. ChemCatChem 2017, 1-12. https://doi.org/10.1002/cctc.201700233.

(43) Han, J.; Cho, J.; Kim, J. C.; Ryoo, R. Confinement of Supported Metal Catalysts at High Loading in the Mesopore Network of Hierarchical Zeolites, with Access via the Microporous Windows. ACS Catal. 2018, $8 \quad$ (2), $876-879$. https://doi.org/10.1021/acscatal.7b04183.

(44) Gallas-Hulin, A.; Mielby, J.; Kegnæs, S. Efficient Production of Hydrogen from Decomposition of Formic Acid over Zeolite Incorporated Gold Nanoparticles. ChemistrySelect 2016, 1 (13). https://doi.org/10.1002/slct.201600831. 
(45) Rasmussen, K. H.; Mielby, J.; Kegnaes, S. Towards Encapsulation of Nanoparticles in Chabazite Through Interzeolite Transformation. ChemCatChem 2018, 10 (19), 4380-4385. https://doi.org/10.1002/cctc.201800914.

(46) Li, S.; Boucheron, T.; Tuel, A.; Farrusseng, D.; Meunier, F. Size-Selective Hydrogenation at the Subnanometer Scale over Platinum Nanoparticles Encapsulated in Silicalite-1 Single Crystal Hollow Shells. Chem. Commun. 2014, $50 \quad$ (15), 1824. https://doi.org/10.1039/c3cc48648f.

(47) Xu, D.; Lv, H.; Liu, B. Encapsulation of Metal Nanoparticle Catalysts Within Mesoporous Zeolites and Their Enhanced Catalytic Performances: A Review. Front. Chem. 2018, 6. https://doi.org/10.3389/fchem.2018.00550.

(48) Gu, J.; Zhang, Z.; Hu, P.; Ding, L.; Xue, N.; Peng, L.; Guo, X.; Lin, M.; Ding, W. Platinum Nanoparticles Encapsulated in MFI Zeolite Crystals by a Two-Step Dry Gel Conversion Method as a Highly Selective Hydrogenation Catalyst. ACS Catal. 2015, 5 (11), 6893-6901. https://doi.org/10.1021/acscatal.5b01823.

(49) Zhou, J.; Hua, Z.; Zhao, J.; Gao, Z.; Zeng, S.; Shi, J. A Micro/Mesoporous Aluminosilicate: Key Factors Affecting Framework Crystallization during Steam-Assisted Synthesis and Its Catalytic Property. J. Mater. Chem. 2010, $20 \quad$ (32), 6764. https://doi.org/10.1039/c0jm00513d.

(50) Matsukata, M.; Ogura, M.; Osaki, T.; Hari Prasad Rao, P. R.; Nomura, M.; Kikuchi, E. Conversion of Dry Gel to Microporous Crystals in Gas Phase. Top. Catal. 1999, 9 (1/2), 77-92. https://doi.org/10.1023/A:1019106421183. 
(51) Naik, S. P.; Chiang, A. S. T.; Thompson, R. W. Synthesis of Zeolitic Mesoporous Materials by Dry Gel Conversion under Controlled Humidity. J. Phys. Chem. B 2003, 107 (29), 70067014. https://doi.org/10.1021/jp034425u.

(52) Thommes, M.; Cychosz, K. A. Physical Adsorption Characterization of Nanoporous Materials: Progress and Challenges. Adsorption 2014, 20 (2), 233-250. https://doi.org/10.1007/s10450-014-9606-z.

(53) Thommes, M. Physical Adsorption Characterization of Nanoporous Materials. ChemieIngenieur-Technik 2010, 82 (7), 1059-1073. https://doi.org/10.1002/cite.201000064.

(54) Thommes, M.; Kaneko, K.; Neimark, A. V.; Olivier, J. P.; Rodriguez-Reinoso, F.; Rouquerol, J.; Sing, K. S. W. Physisorption of Gases, with Special Reference to the Evaluation of Surface Area and Pore Size Distribution (IUPAC Technical Report). Pure Appl. Chem. 2015, 87 (9-10), 1051-1069. https://doi.org/10.1515/pac-2014-1117.

(55) Christensen, C. H.; Johannsen, K.; Schmidt, I.; Christensen, C. H. Catalytic Benzene Alkylation over Mesoporous Zeolite Single Crystals: Improving Activity and Selectivity with a New Family of Porous Materials. J. Am. Chem. Soc. 2003, 125 (44), 13370-13371. https://doi.org/10.1021/ja037063c.

(56) Groen, J. C.; Pérez-Ramírez, J. Critical Appraisal of Mesopore Characterization by Adsorption Analysis. Appl. Catal. A Gen. 2004, 268 (1-2), 121-125. https://doi.org/10.1016/j.apcata.2004.03.031.

(57) Groen, J. C.; Peffer, L. a. .; Pérez-Ramírez, J. Pore Size Determination in Modified Microand Mesoporous Materials. Pitfalls and Limitations in Gas Adsorption Data Analysis. 
Microporous Mesoporous Mater. 2003, 60 (1-3), 1-17. https://doi.org/10.1016/S13871811(03)00339-1.

(58) Janssen, A. H.; Koster, A. J.; de Jong, K. P. On the Shape of the Mesopores in Zeolite Y: A Three-Dimensional Transmission Electron Microscopy Study Combined with Texture Analysis. J. Phys. Chem. B 2002, $106 \quad$ (46), 11905-11909. https://doi.org/10.1021/jp025971a.

(59) Cychosz, K. A.; Guillet-Nicolas, R.; García-Martínez, J.; Thommes, M. Recent Advances in the Textural Characterization of Hierarchically Structured Nanoporous Materials. Chem. Soc. Rev. 2017, 46 (2), 389-414. https://doi.org/10.1039/C6CS00391E.

(60) Rasmussen, C. J.; Vishnyakov, A.; Thommes, M.; Smarsly, B. M.; Kleitz, F.; Neimark, A. V. Cavitation in Metastable Liquid Nitrogen Confined to Nanoscale Pores. Langmuir 2010, 26 (12), 10147-10157. https://doi.org/10.1021/la100268q.

(61) Pulikkal Thumbayil, R.; Mielby, J.; Kegnæs, S. Pd Nanoparticles Encapsulated in Mesoporous HZSM-5 Zeolite for Selective One-Step Conversion of Acetone to Methyl Isobutyl Ketone. Top. Catal. 2019, 62 (7-11), 678-688. https://doi.org/10.1007/s11244019-01153-6.

(62) Chen, H.; Zhang, X.; Zhang, J.; Wang, Q. Controllable Synthesis of Hierarchical ZSM-5 for Hydroconversion of Vegetable Oil to Aviation Fuel-like Hydrocarbons. RSC Adv. 2017, 7 (73), 46109-46117. https://doi.org/10.1039/C7RA08867A.

(63) Wang, Z.; Li, C.; Cho, H. J.; Kung, S.-C.; Snyder, M. A.; Fan, W. Direct, Single-Step Synthesis of Hierarchical Zeolites without Secondary Templating. J. Mater. Chem. A 2015, 
3 (3), 1298-1305. https://doi.org/10.1039/C4TA05031B.

(64) Lucchini, M. A.; Testino, A.; Kambolis, A.; Proff, C.; Ludwig, C. Sintering and Coking Resistant Core-Shell Microporous Silica-Nickel Nanoparticles for CO Methanation: Towards Advanced Catalysts Production. Appl. Catal. B Environ. 2016, 182, 94-101. https://doi.org/10.1016/j.apcatb.2015.09.012.

(65) Wang, W.; Chu, W.; Wang, N.; Yang, W.; Jiang, C. Mesoporous Nickel Catalyst Supported on Multi-Walled Carbon Nanotubes for Carbon Dioxide Methanation. Int. J. Hydrogen Energy 2016, 41 (2), 967-975. https://doi.org/10.1016/j.ijhydene.2015.11.133.

(66) Rostrup-Nielsen, J. R.; Pedersen, K.; Sehested, J. High Temperature MethanationSintering and Structure Sensitivity. Appl. Catal. A Gen. 2007, 330 (1-2), 134-138. https://doi.org/10.1016/j.apcata.2007.07.015.

(67) Shah, M. A. Growth of Uniform Nanoparticles of Platinum by an Economical Approach at Relatively Low Temperature. Sci. $\quad$ Iran. 2012, 19 (3), 964-966. https://doi.org/10.1016/J.SCIENT.2012.02.027. 


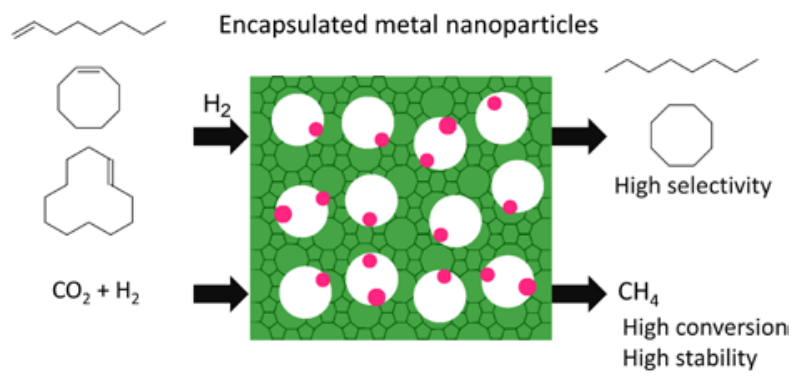

Figure 10: For Table of Contents Only 


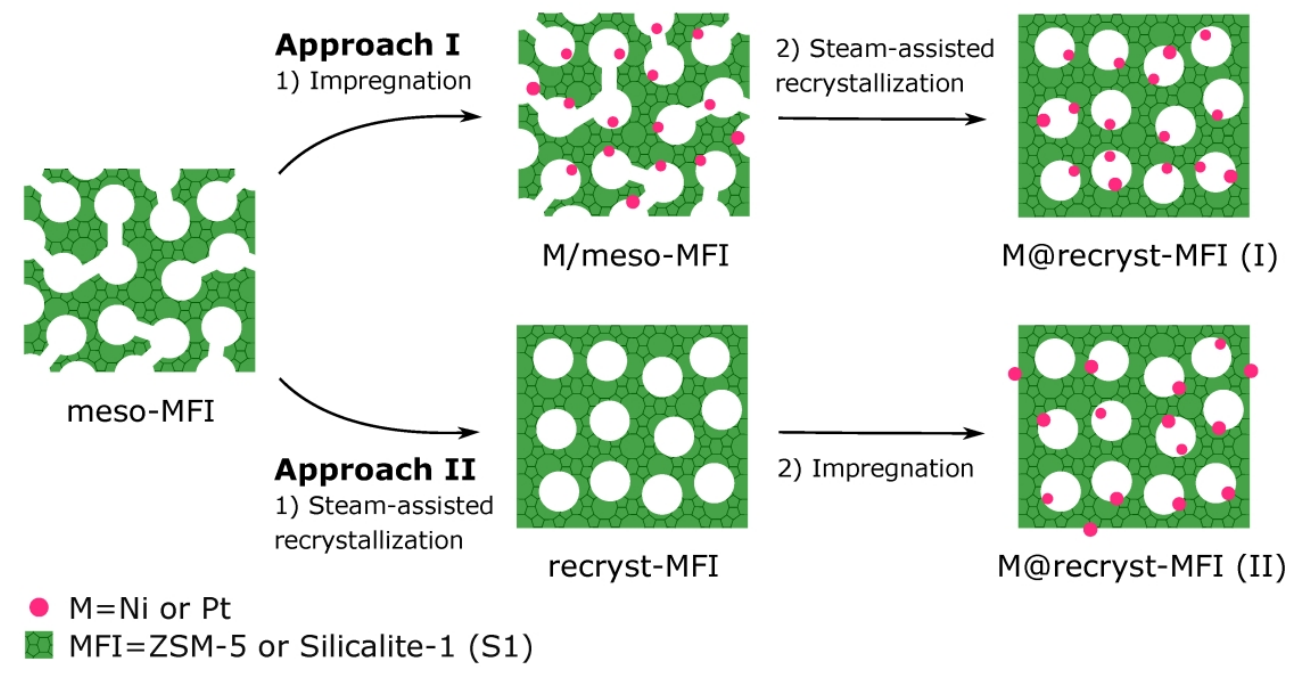

Schematic outline of a general method to encapsulate metal nanoparticles in zeolites.

$305 \times 164 \mathrm{~mm}(300 \times 300 \mathrm{DPI})$ 

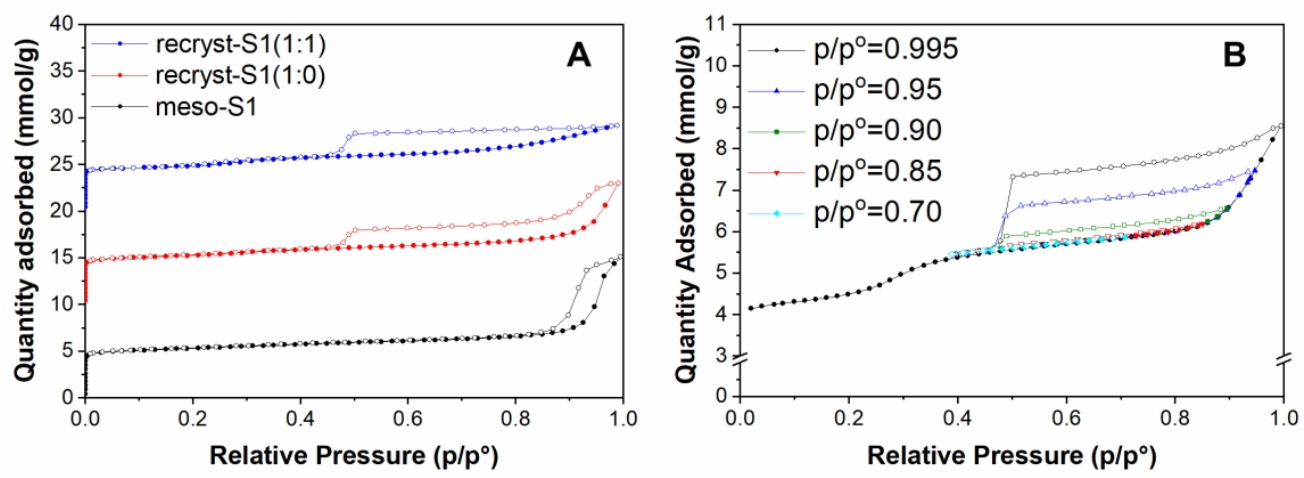

A) N2 physisorption isotherms of meso-S1 (black), recryst-S1(1:0) (red) and recryst-S1(1:1) (blue) and B) hysteresis scan of recryst-S1(1:1). 

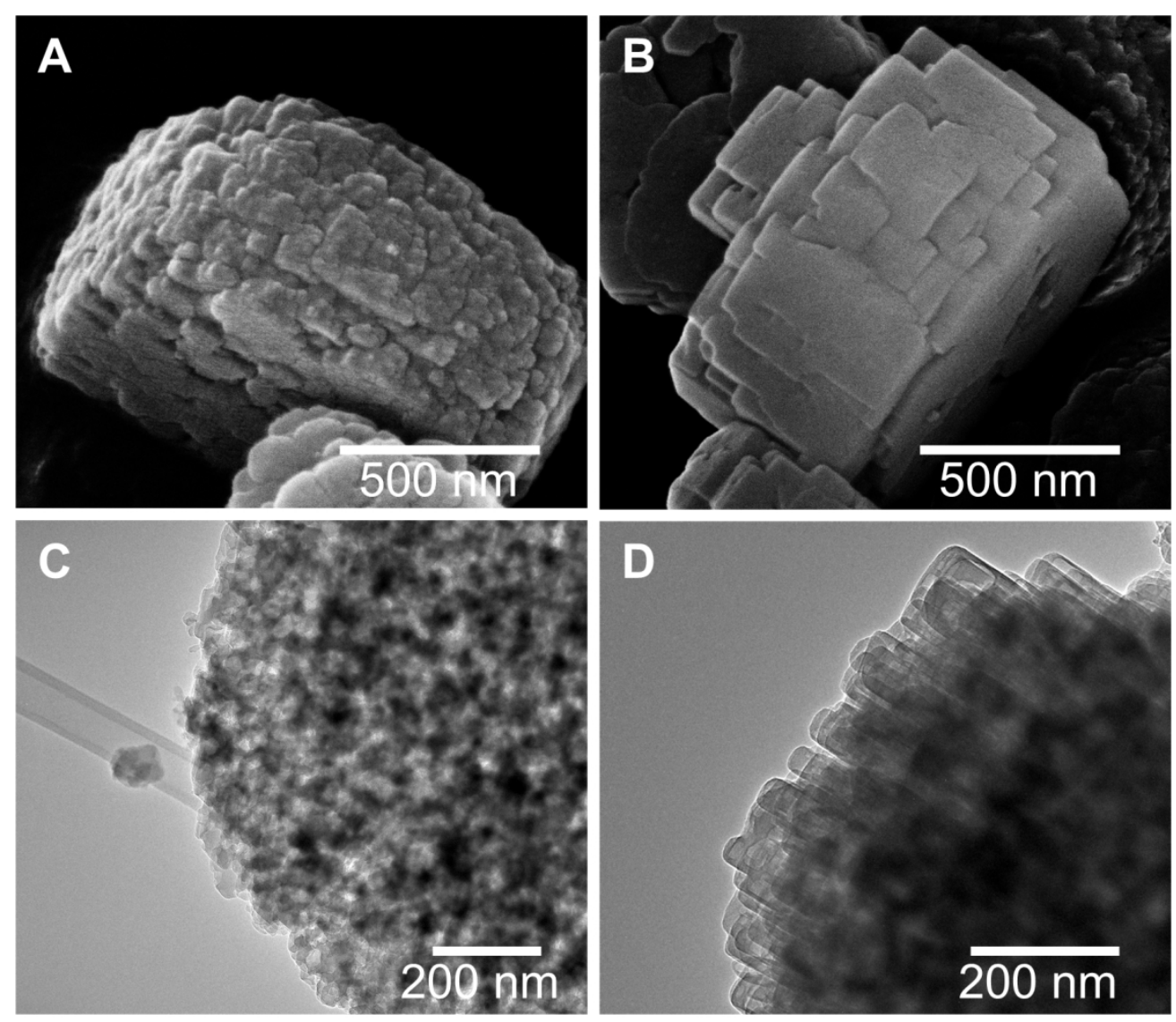

SEM and TEM images of meso-S1 $(A+C)$ and recryst-S1(1:1) $(B+D)$. 

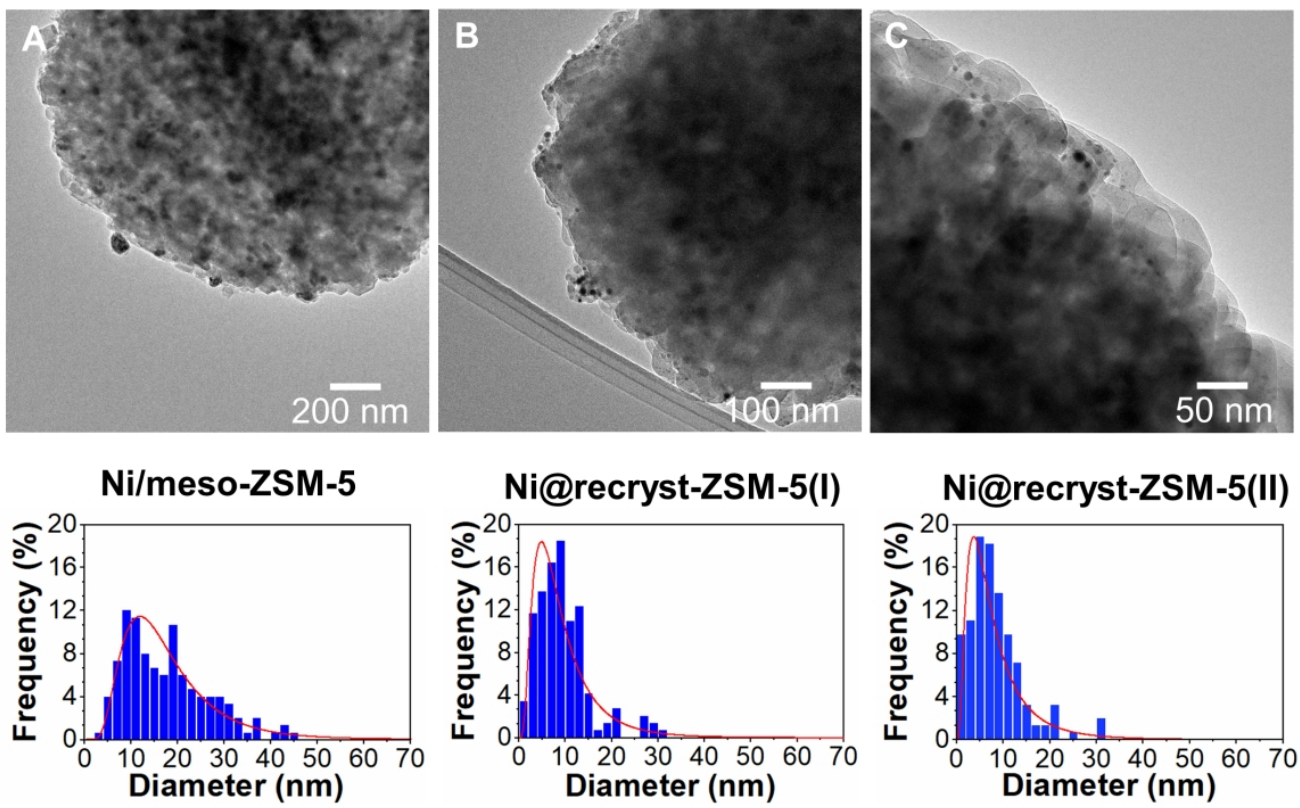

TEM images of A) Ni/meso-ZSM-5, B) Ni@recryst-ZSM-5(I) and C) Ni@recryst-ZSM-5(II) together with their particle size distributions based on the measurement of $>100$ nanoparticles. 

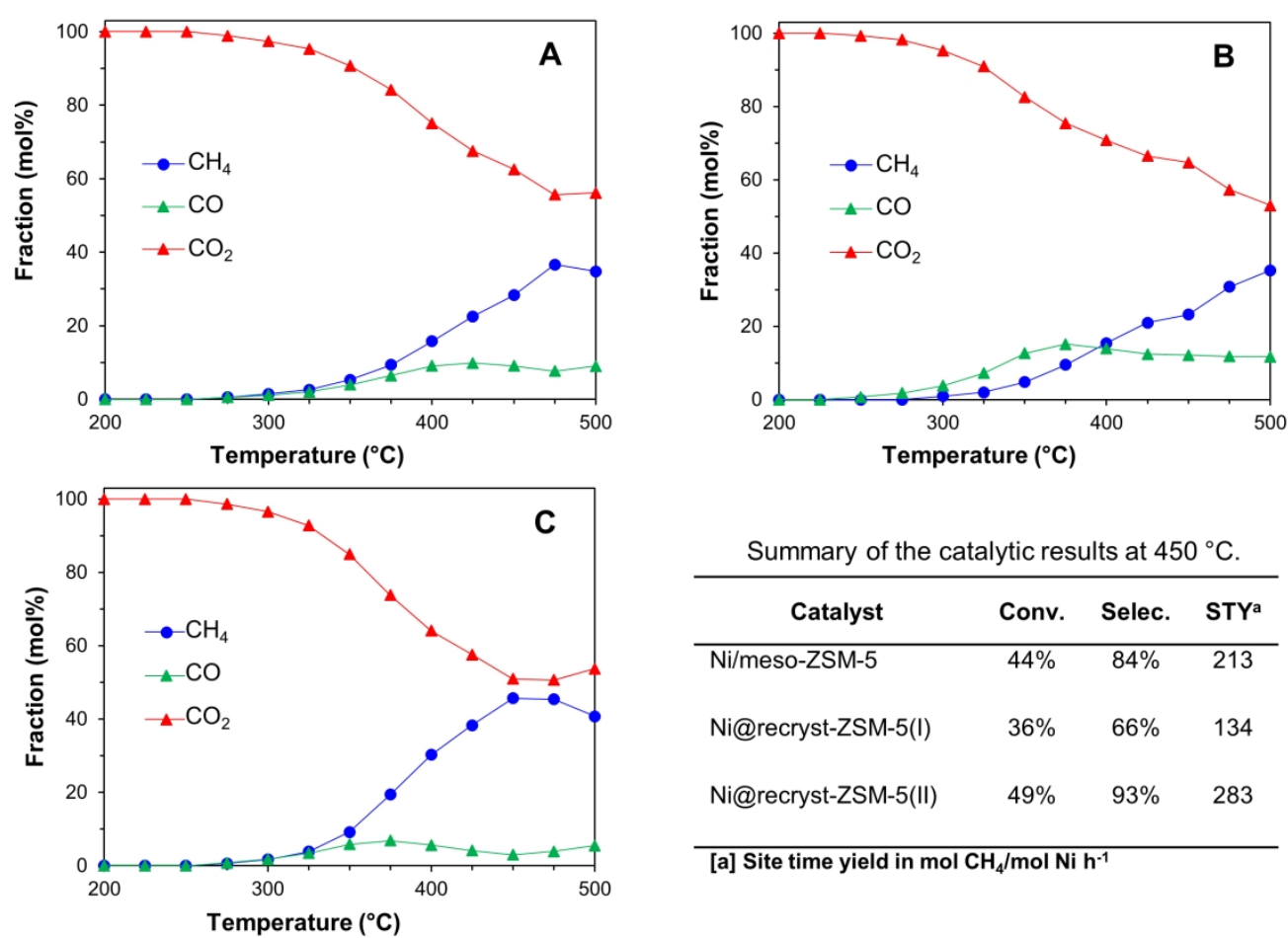

Summary of the catalytic results at $450^{\circ} \mathrm{C}$.

\begin{tabular}{lccc}
\hline \multicolumn{1}{c}{ Catalyst } & Conv. & Selec. & STYa $^{\mathbf{c}}$ \\
\hline Ni/meso-ZSM-5 & $44 \%$ & $84 \%$ & 213 \\
Ni@recryst-ZSM-5(I) & $36 \%$ & $66 \%$ & 134 \\
Ni@recryst-ZSM-5(II) & $49 \%$ & $93 \%$ & 283 \\
\hline & & \\
\hline [a] Site time yield in $\mathrm{mol} \mathrm{CH}_{4} / \mathrm{mol} \mathrm{Ni} \mathrm{h}^{-1}$
\end{tabular}

Product distribution as a function of the temperature for A) Ni/meso-ZSM-5, B) Ni@recryst-ZSM-5(I) and C) $\mathrm{Ni} @$ recryst-ZSM-5(II) together with a summary of the catalytic activity at $450{ }^{\circ} \mathrm{C}$. 

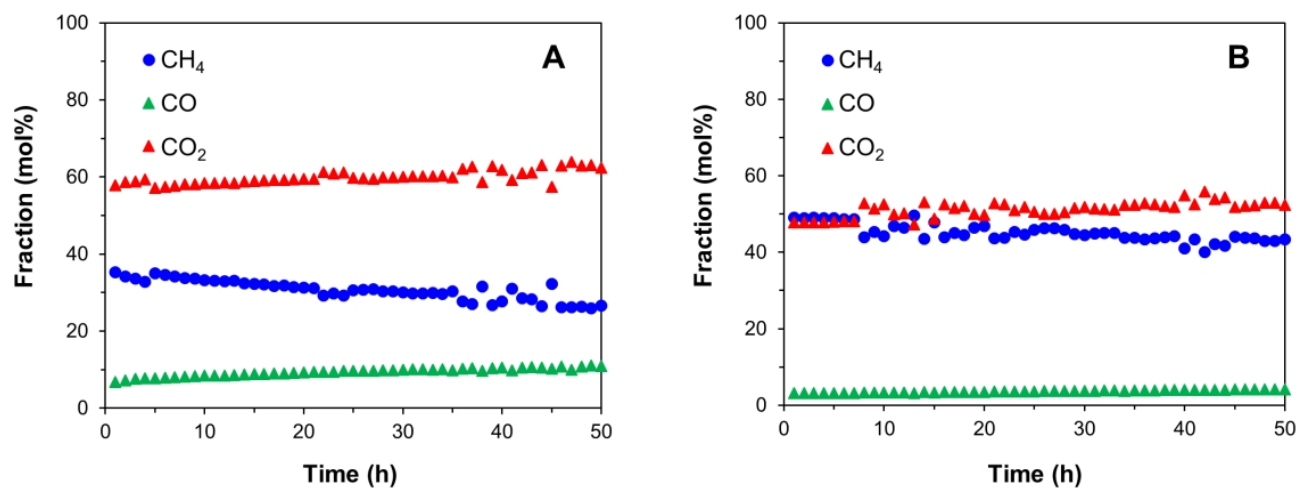

Catalytic stability for A) Ni/meso-ZSM-5 and B) Ni@recryst-ZSM-5(II) over $50 \mathrm{~h}$ at $450{ }^{\circ} \mathrm{C}$. 

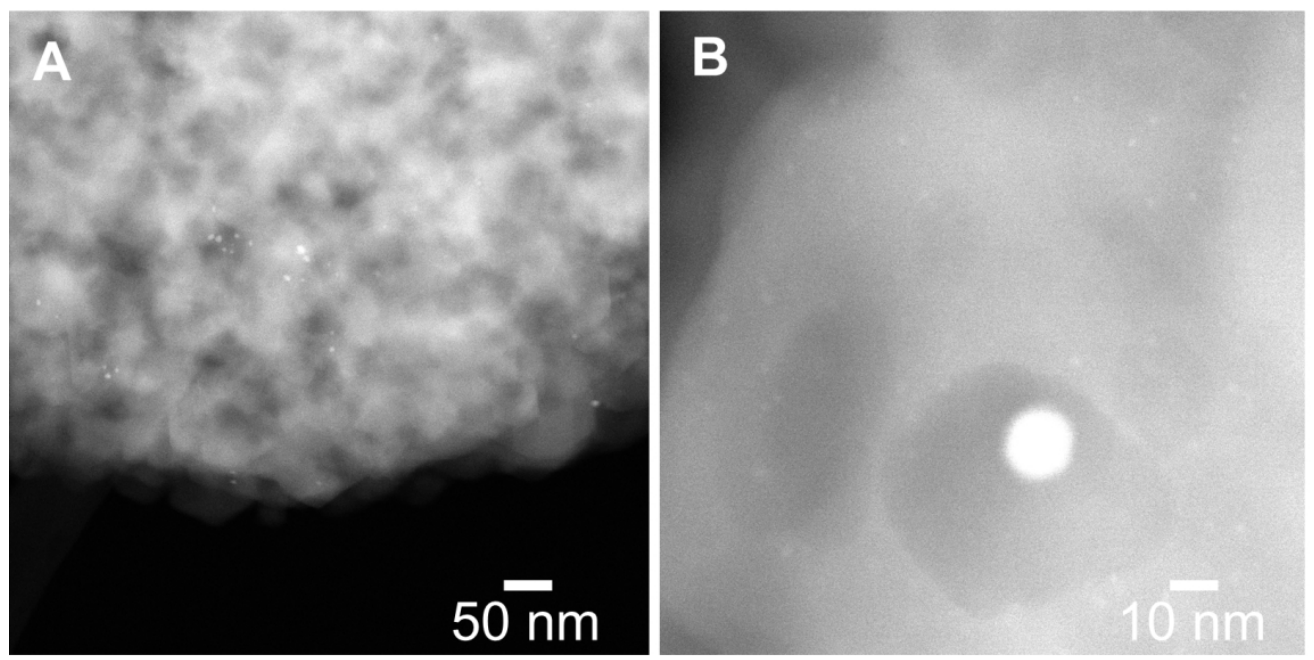

STEM images of Pt/meso-S1 (A) and Pt@recryst-S1(I) (B). 


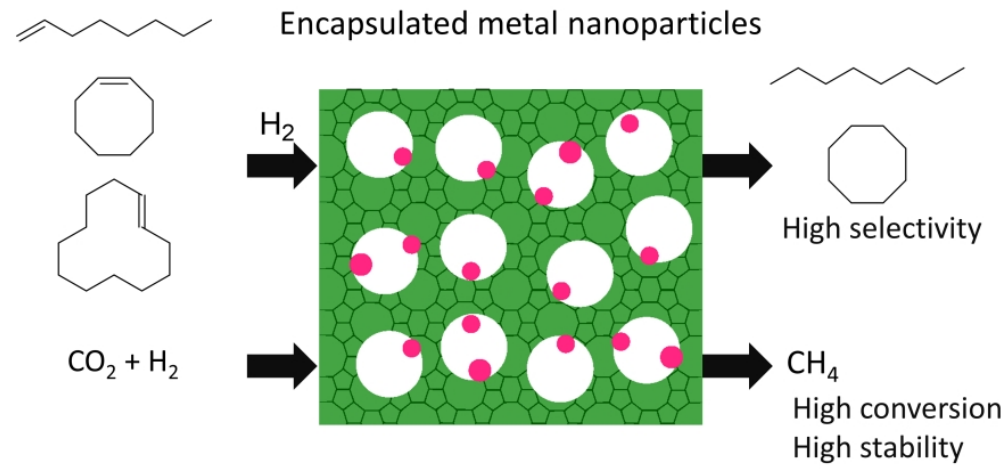

338x190mm (300 x 300 DPI) 